\title{
Simulation of lon Source's Control System on Cyclotron Using Programmable System on Chip (PSoC)
}

\author{
R.S. Darmawan , S. Santosa and Silakhuddin \\ Center for Technology of Accelerator and Material Process, National Nuclear Energy Agency \\ Jl. Babarsari Kotak Pos 6101 Yogyakarta 55281, Indonesia
}

\section{ARTICLE INFO}

Article history:

Received 20 November 2010

Received in Revised form 07 October 2011

Accepted 11 October 2011

Keywords:

Controller

Cyclotron

Ion source

PSoC

Stepper motor

\begin{abstract}
A B S T R A C T
Cyclotron is an ion accelerator machine with spiral beam path. Ion source system is one of the main systems which its function is to produce ions that will be accelerated. In order to obtain maximum ion current, the ion source must be equipped with a control system that control mechanical system that will adjust the position of the ion source. The mechanical system able to make adjustment in three different axis, that is $x, y$ and $z$ axis. The mechanical system consists of a stepper motor and a set of gears. The control system using Programmable System on Chip (PSoC) utilizes its user module from the Random Sequence group, that is 8-bit Pseudo Random Sequence Generator (PRS8).For $x$ and $y$ axis, if the stepper motor rotate one rotation that means the support will be pushed or pulled $2.5 \mathrm{~mm}$. While for $z$ axis if the stepper motor rotate one rotation that means the support will be pushed or pulled $0.83 \mathrm{~mm}$. The largest deviation of the stepper motor is $2^{\circ}$ with error percentage is $1.09 \%$. The mean value of step of the stepper motor is 2.03 step per second.
\end{abstract}

(C) 2011 Atom Indonesia. All rights reserved

\section{INTRODUCTION}

In the early of 2009, Center for Accelerator and Material Process Technology National Nuclear Energy Agency has started to conduct a research about cyclotron to produce radioisotope with energy proton about $13 \mathrm{MeV}$. Cyclotron is an ion accelerator with spiral beam path. Cyclotron's components are magnet system, RF (radio frequency), ion source system, vacuum system, instrumentation and control system and beam extractor system.

The main function of ion source system in to produce hydrogen ion $\left(\mathrm{H}^{+}\right.$or $\left.\mathrm{H}^{-}\right)$ that will be accelerated by the RF system. In the previous research has been studied about the type of ion source and it's dicided that the cyclotorn will apply an cold cathode PIG ion source with radial installation from the side of the vacuum tank.

In order to optimize the function of the ion source to obtain ion as much as possible, the ion source must be equipped with an adjustment system that able to arrange ion source's position. The system should be able to accommodate the movement on the ion source in three axis that is $x, y$ and $z$ axis. The system is divided into two main sub system that is control system and mechanical system. The mechanical system consists of a stepper motor and a set of gears that connect the stepper motor and the ion source. Stepper motor is a synchronous electric motor that can divide a full rotation into a large number of steps. The motor's position can be controlled precisely without any feedback mechanism, as long as the motor is carefully sized to the application. To control stepper motor, it uses programmable system on chip (PSoC). PSoC is a family of integrated circuits made by Cypress Semiconductor. These chips include a CPU and mixed-signal arrays of configurable integrated analog and digital peripherals.

\footnotetext{
* Corresponding author.

E-mail address: riansd@batan.go.id;
} 


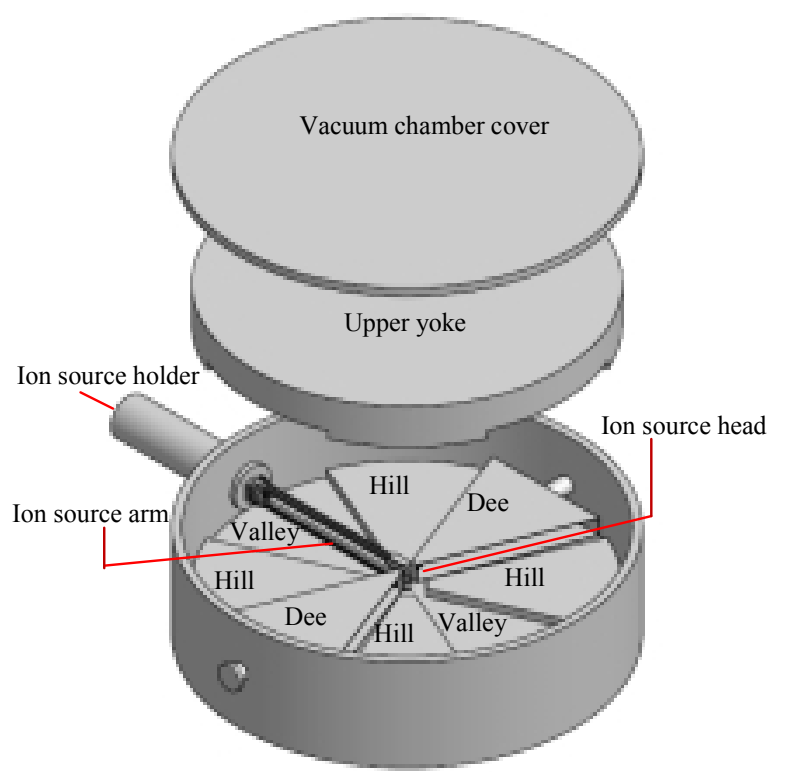

Fig. 1. Position of the ion source in the magnet system of cyclotron

\section{THEORY}

\section{Control system}

A control system is a device or set of devices to manage, command, direct or regulate the behavior of other devices or systems. The term "control system" may be applied to the essentially manual controls that allow an operator, for example to close and open a hydraulic press. An automatic sequential control system may trigger a series of mechanical actuator in the correct sequence to perform a task.

\section{Stepper motor}

A stepper motor is an electromechanical device which converts electrical pulses into discrete mechanical movements. The shaft or spindle of a stepper motor rotates in discrete step increments when electrical command pulses are applied to it in the proper sequence. The motors rotation has several direct relationships to these applied input pulses. The sequence of the applied pulses is directly related to the direction of motor shafts rotation. The speed of the motor shafts rotation is directly related to the frequency of the input pulses and the length of rotation is directly related to the number of input pulses applied.

\section{Open loop operation}

One of the most significant advantages of a stepper motor is its ability to be accurately controlled in an open loop system. Open loop control means no feedback information about position is needed. This type of control eliminates the need for expensive sensing and feedback devices such as optical encoders. Your position is known simply by keeping track of the input step pulses.

\section{Gear ratio}

Gears are generally used for one of four different reasons:

1. To reverse the direction of rotation

2. To increase or decrease the speed of rotation

3. To move rotational motion to a different axis

4. To keep the rotation of two axes synchronized

On any gear, the ratio is determined by the distances from the center of the gear to the point of contact. Understanding the concept of the gear ratio is like understanding the concept of the circumference of a circle. The circumference of a circle is equal to the diameter of the circle multiplied by $\pi$.

$$
C=\pi D
$$

where $C$ is circumference and $D$ is diameter. This equation is to calculate the circumference of a gear. If we obtain the circumference of the gear, we can calculate the gear ratio of a gear.

$$
g r=\frac{\pi D}{\pi d}=\frac{D}{d}
$$

where $g r$ is gear ratio, $D$ is diameter of the driven gear and $\mathrm{d}$ is diameter of the driver gear. This equation is to calculate the gear ratio of two connected gears.

\section{PSoC}

PSoC stands for Programmable System on Chip. PSoC is a programmable embedded systemon-chip integrating configurable analog and digital peripheral functions, memory and a microcontroller on a single chip. The systems them self and the connections between them may 
be configured to achieve a system on chip. Figure 2 show the logic block diagram of PSoC.

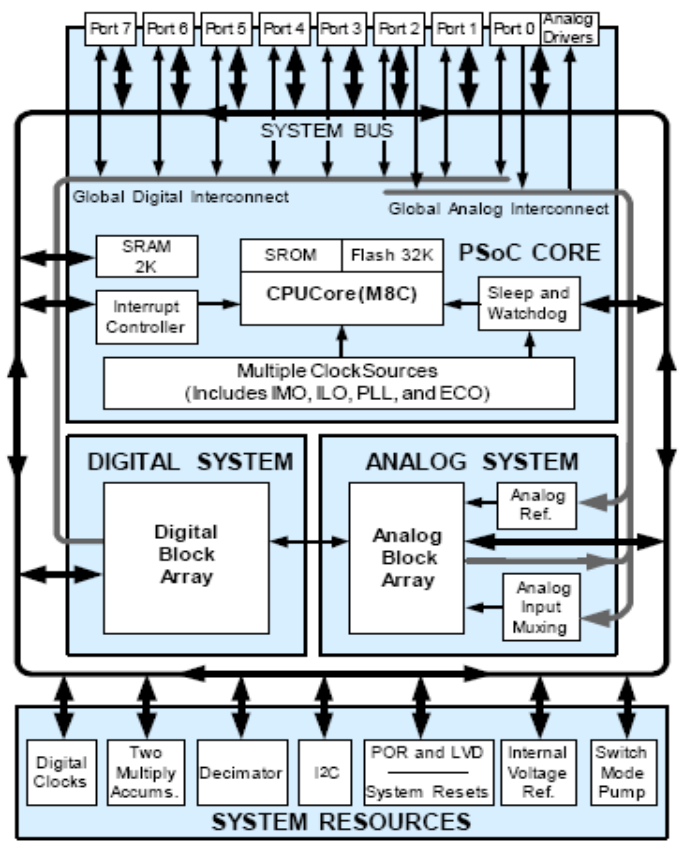

Fig. 2. Logic block diagram of PSoC.

\section{EXPERIMENTAL METHOD}

\section{Mechanical system}

Ion source system has a mechanical system that able to move in three axis that is $x$ (horizontal direction), $y$ (vertical direction) and $z$ axis (forward and backward). The configuration of mechanical system that consist of stepper motor and set of gears in $x$ and $y$ axis are the same, the difference is at the position of the stepper motor and the support. Support is a component that holds the ion source around the holder of ion source system. Support is designed to be able to push or pull the ion source system when the stepper motor is on and still able to hold the ion source system while the other axis are moved. Support for $x$ axis is located in the right side of the holder of ion source system while support for $y$ axis is located under the holder of ion source system. Figure 3, 4 and 5 show the diagram of ion source's mechanical system in $x, y$ and $\mathrm{z}$ axis.

Set of gears for component in $z$ axis consist of two bevel gears with $5 \mathrm{~cm}$ diameter, one spur gear with $5 \mathrm{~cm}$ diameter and one spur gear with $15 \mathrm{~cm}$ diameter. First bevel gear attached to the stepper motor and drive the second bevel gear to change the direction of the shaft. The $5 \mathrm{~cm}$ diameter spur gear installed in the same shaft with the second bevel gear. This $5 \mathrm{~cm}$ diameter spur gear drive the $15 \mathrm{~cm}$ diameter spur gear. The $15 \mathrm{~cm}$ diameter spur gear has thread inside part of the gear that attached with the threaded part of the holder of the ion source. So if the $15 \mathrm{~cm}$ diameter spur gear rotate, it will move the ion source forward or backward.

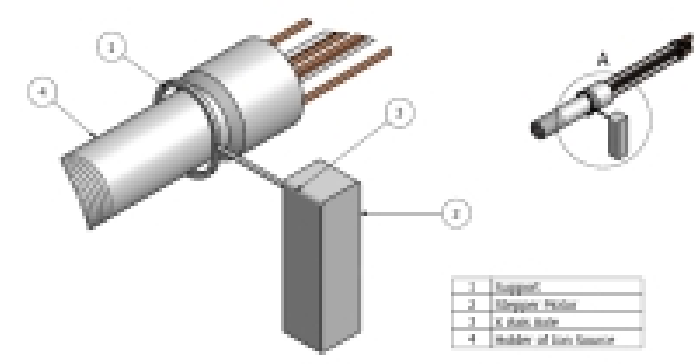

Fig. 3. Diagram of ion source's mechanical system in $x$ axis.
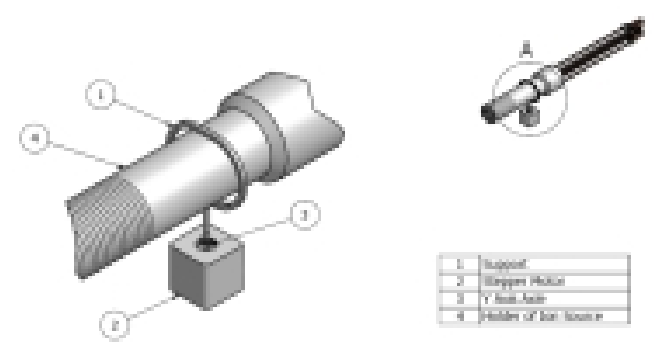

Fig. 4. Diagram of ion source's mechanical system in $y$ axis.
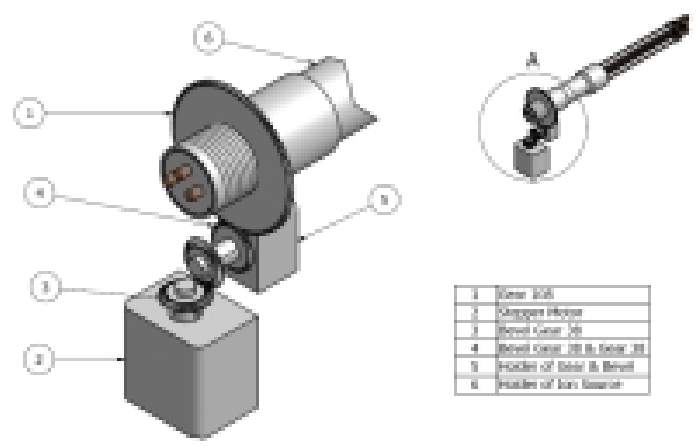

Fig. 5. Diagram of ion source's mechanical system in $z$ axis.

\section{Stepper motor and driver}

In this simulation, the stepper motor that we are using is unipolar type. A unipolar stepper motor 
has two windings per phase, one for each direction of magnetic field. Since in this arrangement a magnetic pole can be reversed without switching the direction of current, the commutation circuit can be made very simple for each winding. Typically, given a phase, one end of each winding is made common: giving three leads per phase and six leads for a typical two phase motor. Often, these two phase commons are internally joined, so the motor has only five leads. Figure 6 show the diagram of stepper motor controller and Fig. 7 unipolar stepper motor driving.

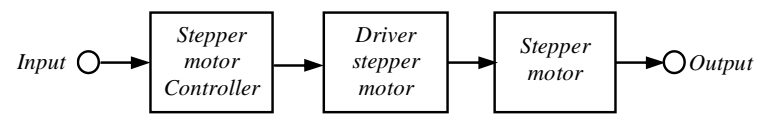

Fig. 6. Diagram of stepper motor controller.

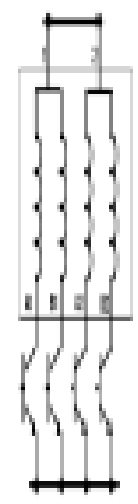

Fig. 7. Unipolar stepper motor driving.

The rotation of stepper motor based on the phase of the stepper motor. PSoC does not have special user module like stepper motor controller. Stepper motor controller build by utilize user module provided by the PSoC. Table 1 show the half step phase and Table 2 show the wave mode phase two phase on.

Table 1. Half step phase.

\begin{tabular}{ccccc}
\hline Step & A1 & A2 & B1 & B2 \\
\hline 1 & 1 & 0 & 0 & 0 \\
2 & 1 & 1 & 0 & 0 \\
3 & 0 & 1 & 0 & 0 \\
4 & 0 & 1 & 1 & 0 \\
5 & 0 & 0 & 1 & 0 \\
6 & 0 & 0 & 1 & 1 \\
7 & 0 & 0 & 0 & 1 \\
8 & 1 & 0 & 0 & 1 \\
\hline
\end{tabular}

Table 2. Wave mode phase and two phase on.

\begin{tabular}{ccccccccc}
\hline & \multicolumn{4}{c}{ Fase Wavemode } & \multicolumn{5}{c}{ Fase Two phase ON } \\
\hline Step & A1 & A2 & B1 & B2 & A1 & A2 & B1 & B2 \\
\hline 1 & 1 & 0 & 0 & 0 & 1 & 1 & 0 & 0 \\
2 & 0 & 1 & 0 & 0 & 0 & 1 & 1 & 0 \\
3 & 0 & 0 & 1 & 0 & 0 & 0 & 1 & 0 \\
4 & 0 & 0 & 0 & 1 & 1 & 0 & 0 & 1 \\
\hline
\end{tabular}

After the last line is reached, the process will be repeated from the first line. The wavemode phase and two phase on recurrent every four bit, while the halfstep phase recurrent every eight bit. Based on those analysis, the controller of stepper motor could be designed by using the shift register. The initial value for the shift register is corresponds with the value for every phase. If shift register be given with clock pulse, then the bit sequence will be shifted out. The bit that shifted out will be re-input in the shift register. After eight clock pulse is given, the value of shift register is equal with the initial value. Figure 8 show the wave mode phase bit sequence in shift register.

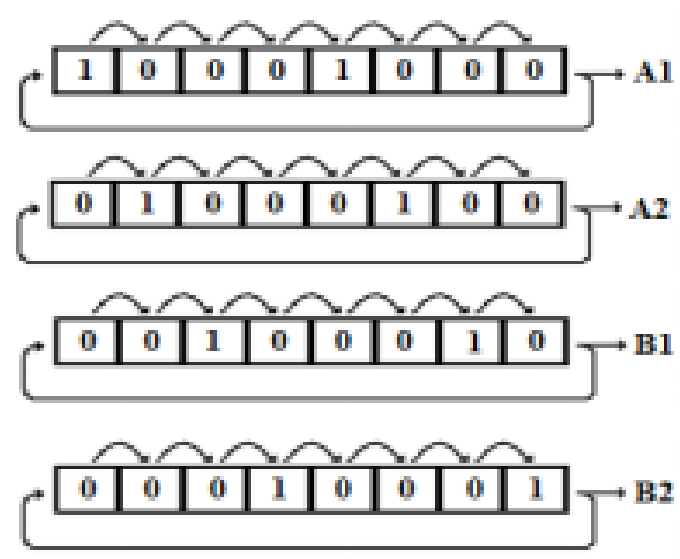

Fig. 8. Wave mode phase bit sequence in shift register.

\section{Design of stepper motor controller}

PSoC does not have shift register user module feature, but PSoC have user module from the Random Sequence group, that is 8-bit Pseudo Random Sequence Generator (PRS8) which act like shift register. Figure 9 show the diagram PRS and Fig. 10 show the wiring of stepper motor controller. Table 3 show the input and output pin of stepper motor controller. 


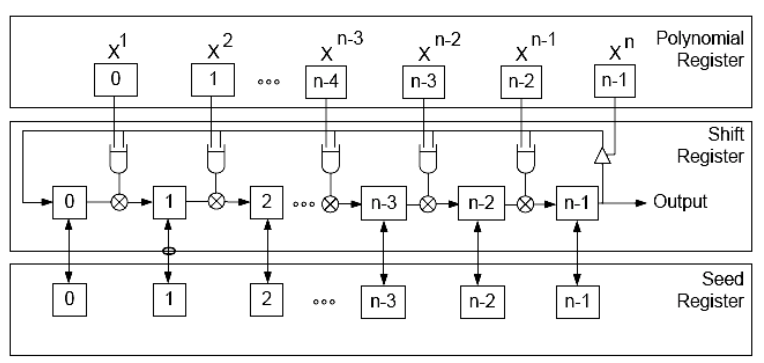

Fig. 9. Diagram PRS.

Table 3. Input and output pin of stepper motor controller.

\begin{tabular}{llll}
\hline \multicolumn{4}{c}{ Input } \\
\hline Pin & Select & Drive & Interrupt \\
\hline P0[0] & StdCPU & Pull Down & DisableInt \\
P0[1] & StdCPU & Pull Down & DisableInt \\
P0[2] & StdCPU & Pull Down & DisableInt \\
\hline \multicolumn{4}{c}{ Output } \\
\hline P2[0] & GlobalOutEven_0 & Strong & DisableInt \\
P2[1] & GlobalOutEven_1 & Strong & DisableInt \\
P2[2] & GlobalOutEven_2 & Strong & DisableInt \\
P2[3] & GlobalOutEven_3 & Strong & DisableInt \\
\hline
\end{tabular}

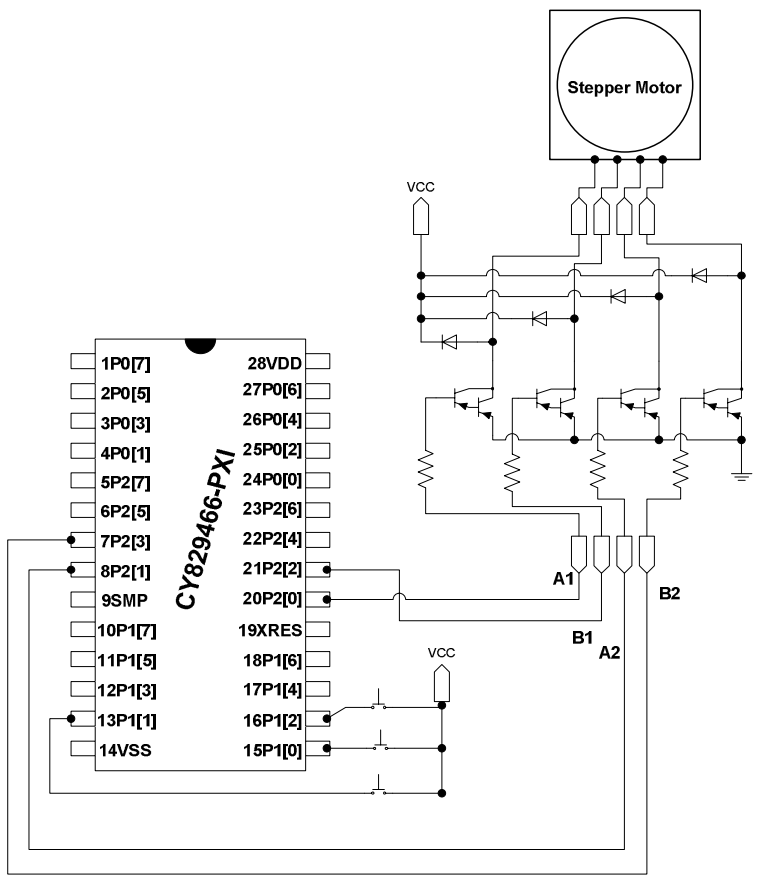

Fig. 10. Wiring of stepper motor controller.

\section{RESULTS AND DISCUSSION}

\section{Mechanical system}

\section{$X$ axis and $Y$ axis}

The configuration of mechanical system that for $x$ and $y$ axis are the same, the difference is only at the position of the stepper motor and the support.
Support is connected to stepper motor with threaded connection. The length of the thread per one revolution is $2,5 \mathrm{~mm}$, so if the stepper motor rotate one rotation that means the support will be pushed or pulled $2,5 \mathrm{~mm}$ depends on the direction of stepper motor rotation. For $x$ axis, the ion source will be moved to the left if the stepper motor rotate in the clockwise direction and vice versa. For $y$ axis, the ion source will be moved upward if the stepper motor rotate in the clockwise direction and vice versa. Table 4 show the simulation of mechanical system for $x$ and $y$ axis.

Table 4. Simulation of mechanical system for $x$ and $y$ axis.

\begin{tabular}{cc}
\hline $\begin{array}{c}\text { Number of rotation of } \\
\text { stepper motor }\end{array}$ & $\begin{array}{c}\text { Distance taken by ion } \\
\text { source }(\mathrm{mm})\end{array}$ \\
\hline 1 & 2,5 \\
2 & 5 \\
3 & 7,5 \\
4 & 10 \\
5 & 12,5 \\
6 & 15 \\
7 & 17,5 \\
8 & 20 \\
9 & 22,5 \\
10 & 25 \\
\hline
\end{tabular}

\section{$Z$ axis}

For the connection between first bevel gear attached to the stepper motor with the second bevel gear, there is no "reduction gear" process because both of them have the same diameter, they only change their direction of the shaft. The $5 \mathrm{~cm}$ diameter spur gear installed in the same shaft with the second bevel gear, so in this connection there is no "reduction gear" process because the $5 \mathrm{~cm}$ diameter spur gear and the second bevel gear have the same diameter, and there is no direction change of the shaft because they installed on the same shaft. For the connection between $5 \mathrm{~cm}$ diameter spur gear (driver gear) with $15 \mathrm{~cm}$ diameter spur gear (driven gear), "reduction gear" process is occur because they have different size of diameter and also change of the shaft direction. From the formula (2), obtained the gear ratio for this connection, that is $3: 1$, so it needs three rotations for the $5 \mathrm{~cm}$ diameter spur gear to rotate $15 \mathrm{~cm}$ diameter spur gear one rotation. The $15 \mathrm{~cm}$ diameter spur gear attached to the holder of the ion source with the threaded connection. The length of the thread per one revolution is $2,5 \mathrm{~mm}$, so if the $15 \mathrm{~cm}$ diameter spur gear rotate one rotation that means the holder of the ion source will be move $2,5 \mathrm{~mm}$ forward or 
backward depends on the direction of stepper motor rotation. From all connection between stepper motor until holder of the ion source, for one rotation of stepper motor, it will move the holder of the ion source $0,83 \mathrm{~mm}$ forward or backward. If the rotation of the stepper motor is clockwise, it will move the ion source backward and vice versa. Table 5 show the simulation of mechanical system for $z$ axis.

Table 5. Simulation of mechanical system for $z$ axis.

\begin{tabular}{cc}
\hline $\begin{array}{c}\text { Number of rotation of } \\
\text { stepper motor }\end{array}$ & $\begin{array}{c}\text { Distance taken by ion } \\
\text { source }(\mathrm{mm})\end{array}$ \\
\hline 1 & 0.83 \\
2 & 1,67 \\
3 & 2.5 \\
4 & 3.33 \\
5 & 4,17 \\
6 & 5 \\
7 & 5,83 \\
8 & 6,67 \\
9 & 7.5 \\
10 & 8.33 \\
\hline
\end{tabular}

\section{Stepper motor, driver and controller}

The stepper motor controller tested by calculating the precision of the stepper motor rotation. The testing is done by calculating the time needed by the stepper motor to do its steps and calculating the radius of the steps. The result of the calculation compared with the specification of the stepper motor. The stepper motor has radius $1,8^{\circ}$ for each step. The measurement of the angle using arc ruler drawn in a piece of paper and a wire with small diameter attached to the shaft of the stepper motor as the degree pointer. Table 6 show the motor stepper testing.

Table 6. Motor stepper testing.

\begin{tabular}{|c|c|c|c|c|c|c|c|c|c|c|}
\hline \multirow{2}{*}{ Steps } & \multirow{2}{*}{ Radius } & \multirow{2}{*}{$\begin{array}{c}\text { Deviation } \\
\text { Radius }\end{array}$} & \multicolumn{6}{|c|}{ Test no (second) } & \multirow{2}{*}{$\begin{array}{c}\text { Mean } \\
\text { of time }\end{array}$} & \multirow{2}{*}{$\begin{array}{l}\text { Step/ } \\
\text { second }\end{array}$} \\
\hline & & & 1 & 2 & 3 & 4 & 5 & 6 & & \\
\hline 10 & $18^{\circ}$ & $0^{\circ}$ & 4.62 & 4.97 & 4.66 & 4.81 & 4.97 & 4.71 & 4.79 & 2.09 \\
\hline 20 & $36^{\circ}$ & $0^{\circ}$ & 9.94 & 9.87 & 9.92 & 9.83 & 10.08 & 9.72 & 9.89 & 2.02 \\
\hline 30 & $53^{\circ}$ & $\begin{array}{c}1^{\circ} \\
(1.85 \%)\end{array}$ & 14.78 & 15.06 & 14.72 & 14.68 & 14.80 & 15.09 & 14.86 & 2.02 \\
\hline 40 & $73^{\circ}$ & $\begin{array}{c}1^{\circ} \\
(1.39 \%)\end{array}$ & 20.19 & 20.30 & 20.28 & 20.29 & 19.54 & 19.65 & 20.04 & 2.00 \\
\hline 50 & $88^{\circ}$ & $\begin{array}{c}2^{\circ} \\
(2.22 \%)\end{array}$ & 25.27 & 24.89 & 25.17 & 24.72 & 24.78 & 24.88 & 24.95 & 2.00 \\
\hline \multicolumn{2}{|c|}{ Mean } & $(1.09 \%)$ & & & & & & & & 2.03 \\
\hline
\end{tabular}

From the table, there is deviation in angle measurement between the experiment and the specification of the stepper motor. The deviation occurs caused by few factors, that is the timer, the accuracy of the measuring paper and the accuracy of the reader. The largest deviation of the experiment is $2^{\circ}$ with error percentage is $1.09 \%$. The mean value of step of the stepper motor is 2.03 step per second. This value is matching with the Counter 16 which set to obtain clock with 0.5 period or $2 \mathrm{~Hz}$ frequency so that the stepper motor yield two steps per second.

\section{CONCLUSION}

For $x$ and $y$ axes, the ion source will be moved to the left if the stepper motor rotate in the clockwise direction and vice versa respectively and if the stepper motor rotate one rotation that means the support will be pushed or pulled $2.5 \mathrm{~mm}$. For $z$ axis, if the rotation of the stepper motor is clockwise, it will move the ion source backward and vice versa and if the stepper motor rotate one rotation it will move ion source $0.83 \mathrm{~mm}$ forward or backward. The largest deviation of the stepper motor is $2^{\circ}$ with error percentage of $1.09 \%$, and the mean value of step of the stepper motor is 2.03 step per second.

\section{REFERENCES}

1. R.S. Darmawan and Silakhuddin, The determination of Ion Source's Specification on Cyclotron, Proceedings in Scientific Meeting and Presentation of Accelerator Technology, Yogyakarta (2009) 1349.

2. Sularso and K. Suga, Basic Design and Choice of Machine Element, PT Pradnya Paramita, Jakarta (1980).

3. G. Niemann, Machine Elements Design and Calculation, in: Mechanica Engineering Vol. II Gears, Springer-Verlag, Berlin-GottingenHeidelberg (1960).

4. http://en.wikipedia.org/wiki/Gears. Retrieved in July (2010).

5. http://en.wikipedia.org/wiki/Gear_ratio. Retrieved in July (2010).

6. http://en.wikipedia.org/wiki/Stepper_motor. Retrieved in July (2010).

7. http://www.psocdeveloper.com/articles/what-ispsoc.html. Retrieved in July (2010). 